\title{
JURNAL DEFORMASI
}

VOL. 1 NO. 2

JULI - DESEMBER 2016

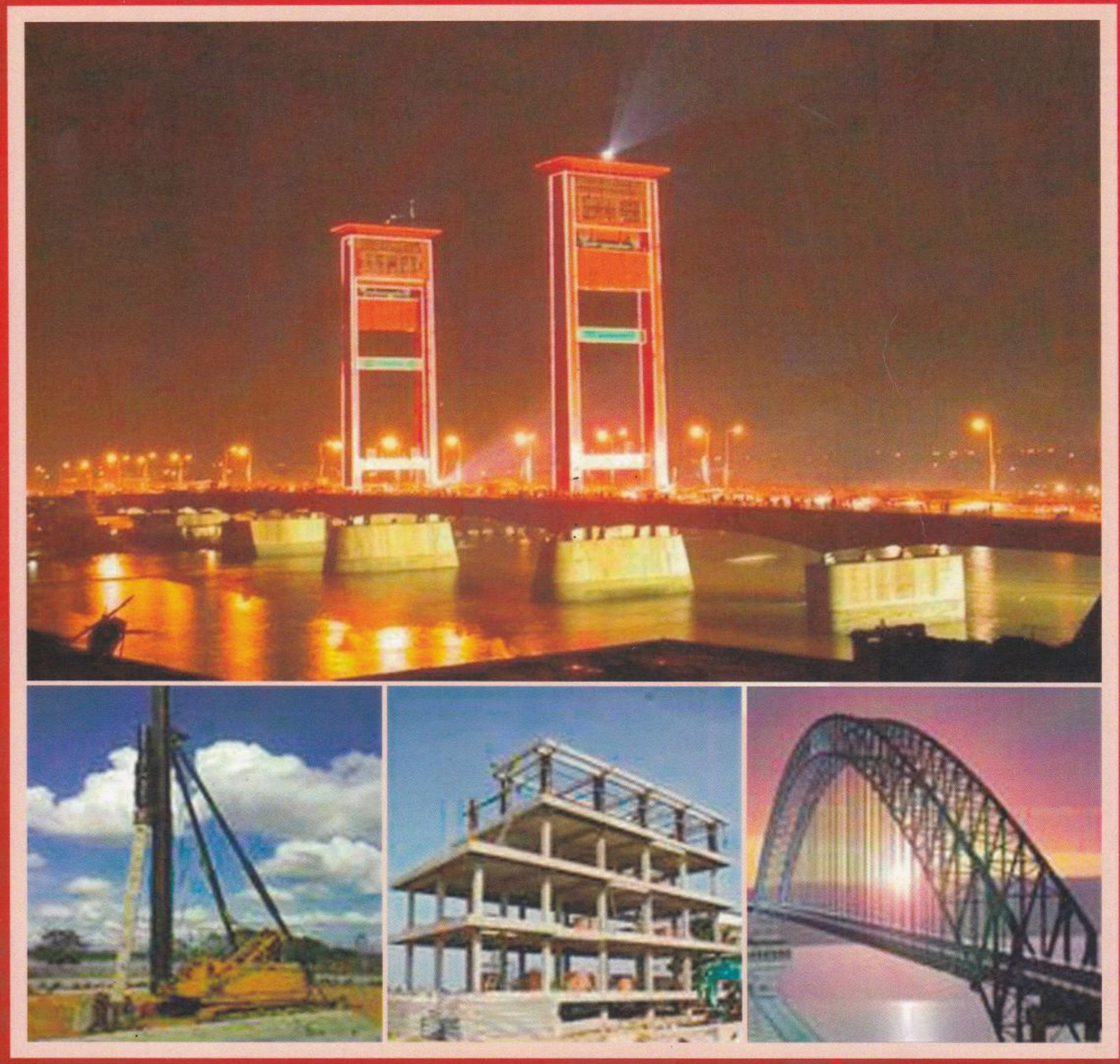




\section{JURNAL DEFORMASI}

Pelindung

Muhammad Firdaus, S.T, M.T

Pengarah

Ir. M. Saleh Al Amin, M.T

Adiguna, S.T, M.Si

Aan Safentry, S.T, M.T

\section{Pimpinan Editorial}

Amiwarti, S.T, M.T

\section{Dewan Editorial}

Ir. K. Oejang Oemar, M.Sc

Herri Purwanto, S.T, M.T

Syahril Alzahri, S.T, M.T

Agus Setiobudi, S.T, M.Si

\section{Mitra Bestari}

Khadavi, S.T, M.T (Universitas Bung Hatta)

Irma Sepriyanna, S.T, M.T (Sekolah Tinggi Teknik PLN)

Ramadhani, S.T, M.T (Universitas Ida Bayumi)

\section{Staf Editorial}

Teddy Irawan, S.T

Endang Kurniawan, S.T

Lisda Ariani, S.T

Alamat Redaksi

Program Studi Teknik Sipil Universitas PGRI Palembang

Jalan Jend. A. Yani Lorong Gotong Royong 9/10 Ulu Palembang Sumatera Selatan Telp. 0711-510043 Fax. 0711-514782, e-mail : Def_15SIPIL@yahoo.com 


\section{JURNAL DEFORMASI}

Volume 1, Nomor 2, Juli 2016 - Desember 2016

\section{DAFTAR ISI}

Artikel Penelitian

Halaman

1. Analisis Area Banjir pada Kawasan Kelurahan Kebun Bunga Palembang, Adiguna. $1-9$

2. Analisis Sistem Pengembangan Pelabuhan Muatan Cair Sungai Lais Palembang, Amiwarti. $10-19$

3. Perbandingan Desain Kekuatan Struktur dan Biaya Pelaksanaan Pembangunan Tower BTS dengan Menggunakan Baja Profil Siku dan Profil Pipa, Herri Purwanto \& Febby Rifalka. $20-30$

4. Rencana Aksi Mitigasi Emisi $\mathrm{CO}_{2}$ dengan skema PARK AND RIDE dan Lajur Khusus Koridor 2 Trans Musi di Kota Palembang, Syahril Alzahri \& Erika Buchari.

5. Studi Perencanaan Kelongsoran Tebing di daerah Empat Lawang STA PI 13+850, Muhammad Firdaus.

6. Tingkat Kinerja Struktur Baja Menara Air Kapasitas $100 \mathrm{M}^{3}$ Di Pabrik Karet PT. MARDEC SIGER WAYKANAN LAMPUNG Terhadap Beban Gempa Berdasarkan SNI 03-1726-2012, Sapta, Sari Firlianti. 


\title{
Petunjuk Untuk Penulis
}

\section{A. Naskah}

Naskah yang di ajukan oleh peneliti harus diketik dengan komputer mengunakan bahasa Indonesia yang baik dan benar, menyertakan 1 (satu) soft copy dalam bentuk CD memakai program microsoft word dan ukuran kertas A4, jarak 1,15 spasi, mengunakan huruf Times New Roman dengan mencantumkan nomor HP/Telepon dan alamat e-mail.

Naskah yang diajukan oleh peneliti merupakan naskah asli yang belum pernah diterbitkan maupun sedang dalam proses pengajuan ditempat lain untuk diterbitkan, dan diajukan minimal 1 (satu) bulan sebelum penerbitan.

\section{B. Format Penulisan Artikal}

\section{Judul}

Judul ditulis dengan huruf besar, nama penulis tanpa gelar, mencantumkan instansi asal, e-mail dan ditulis dengan huruf kecil

\begin{abstract}
Abstrak
Abstrak ditulis dalam bahasa Indonesia antara 100-250 kata, dan berisi pernyataan yang terdapat dalam isi tulisan, menyatakan tujuan dari penelitian, prosedur dasar (pemilihan objek yang diteliti, metode pengamatan dan analisis), ringkasan isi dan kesimpulan dari naskah, menggunakan huruf Times New Roman 10, spasi tunggal
\end{abstract}

\section{Kata Kunci}

Minimal 3 (tiga) kata kunci ditulis dalam bahasa Indonesia

\section{Isi Naskah}

Naskah hasil penelitian dibagi dalam 5 (lima) sub judul, Pendahuluan, Metode Penelitian, Hasil Pembahasan dan Kesimpulan. Penulis menggunakan standar Internasional (misal untuk satuan tidak menggunakan feet tetapi meter, menggunakan terminologi dan simbol diakui internasional (Contoh hambatan mengunakan simbol R), Bila satuan diluar standar SI, dibuat dalam kurung $($ misal $=1$ Feet $(\mathrm{m}))$. Tidak menulis singkatan atau angka pada awal kalimat, tetapi ditulis dengan huruf secara lengkap, Angka yang dilanjutkan dengan simbol ditulis dengan angka Arab, misal $3 \mathrm{~cm}, 4 \mathrm{~kg}$. Penulis harus secara jelas menunjukkan rujukan dan sumber rujukan secara jelas. 


\section{Daftar Pustaka}

Rujukan / Daftar pustaka ditulis dalam urutan angka, tidak menurut alpabet, dengan ketentuan seperti dicontohkan sbb :

1. Standar Internasional :

IEC 60287-1-1 ed2.0; Electric cables - Calculation of the current rating Part $1-1$; Current rating equations (100\% load factor) and calculation of losses - General, Copyright (C) International Electrotechnical Commision (IEC) Geneva, Switzerland, www.iec.ch, 2006

2. Buku dan Publikasi :

George J Anders; Rating of Electric Power Cables in Unfavorable Thermal Environment, IEEE Press, 445 Hoes Lane, Piscataway, NJ 08854, ISBN 0-471-6790-7, 2005

3. Internet :

Electropedia; The World's Online Electrotechnical Vocabulary, http://www.electropedia.org, diakses 15 Maret, 2011

Setiap pustaka harus dimasukkan dalam tulisan. Tabel dan gambar dibuat sesederhana mungkin. Kutipan pustaka harus diikuti dengan nama pengarang, tahun publikasi dan halaman kutipan yang diambil, Kutipan yang lebih dari 4 baris, diketik dengan spasi tunggal tanpa tanda petik. 


\title{
ANALISIS SISTEM PENGEMBANGAN PELABUHAN MUATAN CAIRSUNGAI LAIS PALEMBANG
}

\author{
Amiwarti \\ Dosen Fakultas TeknikSipil Universitas PGRI Palembang \\ Jalan Jend A. Yani Lr. Gotong Royong 9/10 Ulu Palembang Sumatera Selatan \\ Email:Amiwarti@yahoo.com
}

\begin{abstract}
ABSTRAK
Pelabuhan merupakan sarana penting dalam perkembangan suatu wilayah. Pelabuhan Sungai Lais merupakan pelabuhan di kota Palembang yang perlu dikembangkan, karena kondisi sarana yang ada sekarang sangat minim untuk kegunaan secara optimal dalam usaha jasa pelabuhan.Dalam penelitian ini pendekatan yang digunakan adalah penelitian ekperimental yang dilakukan terhadap variabel masa yang akan datang, variabel yang sesungguhnya belum terjadi tetapi sengaja diadakan dalam bentuk perlakuan cobacoba yang terjadi dalam eksperimenyaitu dengan cara menganalisis berbagai aspek dari kawasan yang dimaksud, menganalisis peluang investasi dengan system Hirarki menggunakan need model yang dibutuhkan dan pohon keputusan untuk dapat menghasilkan suatu kesimpulan akhir dari apa yang telah dianalisis. Dan hasil analisis menunjukkan bahwa pelabuhan Sungai Lais layak untuk dikembangkan dengan melihat potensi yang ada dikawasan tersebut.
\end{abstract}

Kata Kunci :Hirarki system, Pohon Keputusan, Need Model,investasi

\section{PENDAHULUAN}

Aspek-aspek yang tercakup dalam fungsi manajemen proyek dalam pencapaian sasaran yang meliputi kualitas, waktu dan biaya merupakan faktor yang menentukan keberhasilan penyelenggaraan suatu proyek, menurut Soekirno, P (2008,hal :1), Kegiatan proyek dapat diartikan sebagai suatu kegiatan sementara yang berlangsung dalam jangka waktu terbatas dengan alokasi sumber daya tertentu dimaksudkan untuk melaksanakan kegiatan yang dapat berupa pembangunan, penelitian, pembuatan produk baru ataupun pengembangan.

Infrastruktur yang merujuk pada sistem fisik yang menyediakan transportasi pengairan, drainase, bangunan gedung dan fasilitas publik lain yang dibutuhkan untuk memenuhi kebutuhan dasar manusia dalam lingkup sosial dan ekonomi, (Satyawan,A,2012). Menurut (APWA), Sistem infrastruktur merupakan pendukung utama sistem sosial dan sistem ekonomi dalam kehidupan sehari-hari masyarakat. Sistem merupakan kumpulan subsistem (komponen) yang saling dihubungkan dengan suatu jenis interaksi atau interelasi dan secara kolektif memberikan respons terhadap stimulus atau permintaan (demand) dan menyandang suatu maksud atau fungsi tertentu, Farida, P,2006 (hal :15).

Perencanaan desain suatu sistem meliputi pengambilan keputusan mengenai bagaimana sumber daya harus digunakan atau ditransformasikan untuk mencapai beberapa tujuan rencana akhirnya (desain akhir) merupakan pemilihan terhadap suatu kombinasi tertentu dari sumber daya dan cara penggunaannya, yang diseleksi diantara kombinasi- 
kombinasi yang ada untuk mencapai tujuan yang sama.Suatu fungsi produksi menyatakan transformasi yang secara teknik efisien dari berbagai sumber daya fisik yang menjadi produk. Menurut Farida,P,2006(hal:12) fungsi produksi adalah tempat kedudukan dari suatu Kombinasi yang secara teknis efisien dari berbagai sumber daya, fungsi produksi menyatakan transformasi yang secara teknik efisien dari berbagai sumber fisik menjadi produk. Efisiensi teknik merupakan semua input yang digunakan berada dalam kinerja maksimal. Efisiensi ekonomis meliputi tranformasi input yang menghasilakn out put secara ekonomis paling efisien. Fungsi produksi dengan single out put membentuk fungsi :

$\mathrm{Y}=\mathrm{g}(\mathrm{x})=\mathrm{g}(\mathrm{x} 1, \ldots ., \mathrm{x} 2, \ldots . . \times 3)$

Dimana $\mathrm{Y}=$ Produk

$\mathrm{X}=$ vektor dari $\mathrm{n}$ sumber daya yang berbeda $\mathrm{X}$

Menurut Idris,Y.2005 (hal : 4), pendekatan sistem adalah cara berfikir yang memungkinkan penyelesaian suatu masalah yang kompleks dengan mengidentifikasi hubungan-hubungan sistemiknya. Prosedur pendekatn sistem meliputi :

1. Pendefinisian sistem yang dilakukan dengan memberikan deskripsi mengenai apakah sistem yang ditinjau itu dan apa yang dilakukan serta menentukan batas sistem apa yang ada didalam dan apa yang ada diluar sistem.

2. Identifikasi bagian-bagian komponen sistem diantaranya input terhadap sistem, proses-proses konversi yang digunakan sistem untuk mentranfurmasikan input menjadi output.

3. Pendefinisian Lingkungan sistem, yaitu apa yang berada diluar sistem dinyatakan dengan dampak elemen-elemen diluar sistem dan terhadap sistem sebaliknya.

Membentuk hirarki sistem dengan menentukan bagian- bagian dari masalah suatu sistem yang besar, sub sistem dan hal yang terkait, Pelindo II, 2002(hal:6). Menurut Tana,H 2010,(hal: 2), sebuah model keputusan semata-mata menupakan alat untuk "meringkaskan" sebuah masalah keputusan dengan cara memungkinkan identifikasi dan evaluasi yang sistematis terhadap semua alternatif keputusan dari sebuah masalah.

Strategi pembangunan kota diharapkan dapat menjelaskan mengenai metode dan teknik yang paling tepat untuk anti pasti optimalisasi lahan untuk pengembangan pelabuhan, dikarenakan kondisi pelabuhan Bom Baru hampir mencapai optimum. Hal ini karena keterbatasan lahan yang ada. Untuk mengantisipasi keperluan penanganan muatan cair khususnya minyak sawit yang dihasilkan. Maka diperlukan pengembangan kawasan, dimana pelabuhan sungai Lais memiliki luas lahan $200 \mathrm{Ha}$.

Dalam rangka memenuhi kebutuhan akan pelayanan muatan cair khususnya minyak sawit atau crude palm oil (CPO). Pelabuhan sungai Lais merupakan kawasan yang akan dikembangkan, dimana sasaran yang hendak dicapai adalah agar dapat menghasilkan suatu keputusan yang tepat untuk peluang investasi. Evaluasi peluang investasi yang dilakukan hanya berdasarkan analisa sosial budaya, analisa teknik dan analisa ekonomi,penilaian hanya berorientasi pada đata yang ada.

\section{METODE PENELITIAN}

Metode Penelitian menggambarkan bagaimana suatu penelitian ditempuh dari awal hingga akhir penelitian, Sigit,S,1999(hal:6). Penelitian ini lebih bersifat ekperimental, menurut Arikunto, 1998 (hal : 17), penelitian ekperimental adalah penelitian yang dilakukan 
terhadap variable masa yang akan datang, variable yang sesungguhnya belum terjadi tetapi sengaja diadakan dalam bentuk perlakuan coba-coba yang terjadi dalam eksperimen. Dengan memperhatikan kajian terhadap berbagai aspek yang ada dan mengidentifikasi peluangpeluang investasi diambil suatu keputusan yang dievaluasi dengan menggunakan pohon keputusan. Tahapan dalam penelitian ini meliputi :

- Pengumpulan data primer dan data skunder.

- Kajian terhadap lingkungan hirarki system yang meliputi kajian kendala system, sumber daya dan kebutuhan system.

- Evaluasi terhadap investasi meliputi analisa sosial budaya, ekonomi dan teknik.

- Analisis dengan pohon keputusan dan fungsi produksi .

- Menarik kesimpulan.

\section{HASIL DAN PEMBAHASAN}

\section{Tinjauan Kondisi Eksiting Pelabuhan}

Pelabuhan sungai Lais terletak di sungai Musi lebih kurang $100 \mathrm{~km}$ dari muara sungai musi kearah hulu. Pelabuhar sungai lais termasuk dalani wilayah Administratif kota Palembang. Kepemilikan lahan pada kawasan perencanaan bervariasi yaitu sebagian besar dimiliki oleh masyarakat setempat dan pemerintah. Kepadatan penduduk masih cukup rendah, karenanya dengan penyertaan masyarakat untuk ikut berpartisipasi dalam pengembangan kawasan tersebut diharapkan gejolak sosial yang terjadi dapat dioptimalkan.

Sedangkan komposisi tata guna lahan pelabuhan sekarang meliputi :

$182 \mathrm{Ha}$, daerah yang belum dioptimalkan pemanfaatannya

$18 \mathrm{Ha}$, daerah yang telah dikembangkan untuk fasilitas pelabuhan dan perkantoran.

Tabel 1.Luas Area Pelabuhan Sungai Lais Palembang

\begin{tabular}{|c|c|c|c|}
\hline No & URAIAN! & LUAS $\left(\mathrm{M}^{2}\right)$ & KETERANGAN \\
\hline 1. & $\begin{array}{l}\text { Luas daerah daratan } \\
\text { Tanah didaerah lingkungan kerja } \\
\text { pelabuhan } \\
\text { Tanah diluar lingkungan kerja } \\
\text { pelabuhan } \\
\text { Tanah penunjang operasional }\end{array}$ & $\begin{array}{l}2.246 .154 \\
31.336\end{array}$ & $\begin{array}{l}\text { Bom baru dan sungai Lais } \\
\text { Tanjung Buyut }\end{array}$ \\
\hline 2 & $\begin{array}{l}\text { Luas areal perairan } \\
\text { Yang telah diusahakan } \\
\text { Dalam upaya diusahakan }\end{array}$ & $\begin{array}{l}495.616 \\
97.827 \\
\end{array}$ & \\
\hline 3 & Alur pelayaran & 10.526 .576 & . \\
\hline
\end{tabular}

\section{Kajian Lingkungan Hirarki Sistem}

Hirarki sistem pengembangan pelabuhan muatan cair sungai Lais meliputi infrastruktur, letak tata ruang dan pihak-pihak yang terkait.

1. Infrastruktur, Infrastruktur kawasan meliputi transportasi, kantor pelabuhan, dermaga, gudang, jalan penghubung, fasilitas tangki CPO, Jetty serta areal parkir

2. Lingkungan pengembangan pelabuhan muatan cair didesain dengan memperhitungkan kondisi lingkungan yaitu berupa rawa-rawa, persawahan dan sungai. 
3. Pendanaan dan Pelaksanaan, pola pendanaan dan pelaksanaan yang dapat mendukung kegiatan pengembangan pelabuhan muatan cair adalah sumber dana dari PT. Pelindo II, kerjasama dengan pihak swasta dan bantuan dari pemerintah.

4. Tata Ruang sistem pengembangan pelabuhan Sungai Lais meliputi daerah pemukiman yang penduduknya belum relative banyak, daerah terbuka dan daerah kawasan industri yang meliputi kabupaten Musi Rawas, kabupaten Muara Enim, kabupaten Musi Banyuasin, Kabupaten Ogan ilir dan kabupaten Ogan Ulu.

\section{Kajian Kendala Sistem}

Pendangkalan dari tikungan pada alur tertentu menyebabkan sulitnya muver sehingga membatasi olah gerak, draft dan panjang kapal, dengan karakteristik dan dimensi yang dimiliki oleh alur pelayaran sungai Musi, panjang alur $\pm 110 \mathrm{~km}$ dan lebar alur $100 \mathrm{~m}$.

Gejala alam berupa asap dimusim kemarau yang mengganggu jadwal dan keselamatan mengantipasi hal ini pihak penyelenggara pelabuhan melakukan pengaturan trafik dengan pola satuhari keluar dari pelabuhandan hari berikutnya jadwal satu kapal-kapal memasuki pelabuhan.

Volume pengerukan yang sangat besar, hampir setiap tahun total volume pengerukan yang harus dikeruk untuk mencapai kedalaman $-6,5 \mathrm{~m} \mathrm{LWS}\left( \pm 2\right.$ juta $\mathrm{m}^{3}$ lumpur bercampur pasir halus), dan pembebanan biaya pengerukan sungai musi selain didànai oleh pemerintah pusat melalui dirjen perhubungan laut dan didanai dengan system sidikasi yaitu melalui kerjasama dengan PT.PUSRI, PERTAMINA, PT.PELINDO II, PT. SEMEN BATURAJA, PT. BUKIT ASAM yang dikoordinir oleh pihak pemerintah daerah Sumatera Selatan.

\section{Kajian Sumber Daya}

Daerah Sungai lais mempunyai potensi yang dapat menjadi aset dalam pergembangan kawasan yaitu sebagai berikut :

Merupakan kawasan yang belum terbangun dan banyak lahan kosong.

Kawasan sungai Lais merupakan kawasan yang strategis dan berpotensi untuk dapat cepat berkembang.

Mempunyai kepadatan penduduk yang relative rendah yaitu 2 jiwa per hektar.

\section{Sumber Daya Manusia}

Pihak-pihak yang terkait dalam pengembangan kawasan ini adalah pemerintah, masyarakat dan swasta. Dengan adanya program pengembangan ini, masyarakai dapat diberdayakan dan tidak tergusur. Sedangkan pihak swasta mendapat peluang sekaligus jaminan keamanan dalam menanamkan investasinya, karenanya pemerintah memperoleh keringanan dalam menyediakan dana pembangunan dan secara otomatis dapat meningkatkan pendapatkan asli daerah.

Pemerintah memberi dukungan dari segi perbaikan dan peningkatan jalan, promosi dan perencanaan (design zona). Pihak swasta memberikan dukungan dalam bidang permodalan dan pembangunan infrastruktur, sedangkan dukungan dari nihak masyarakat dapat berupa penyediaan lahan untuk infrastruktur, keamanian lingkungan, memelihara lingkungan serta menjaga dan mendukung pembangunan infrastruktur 


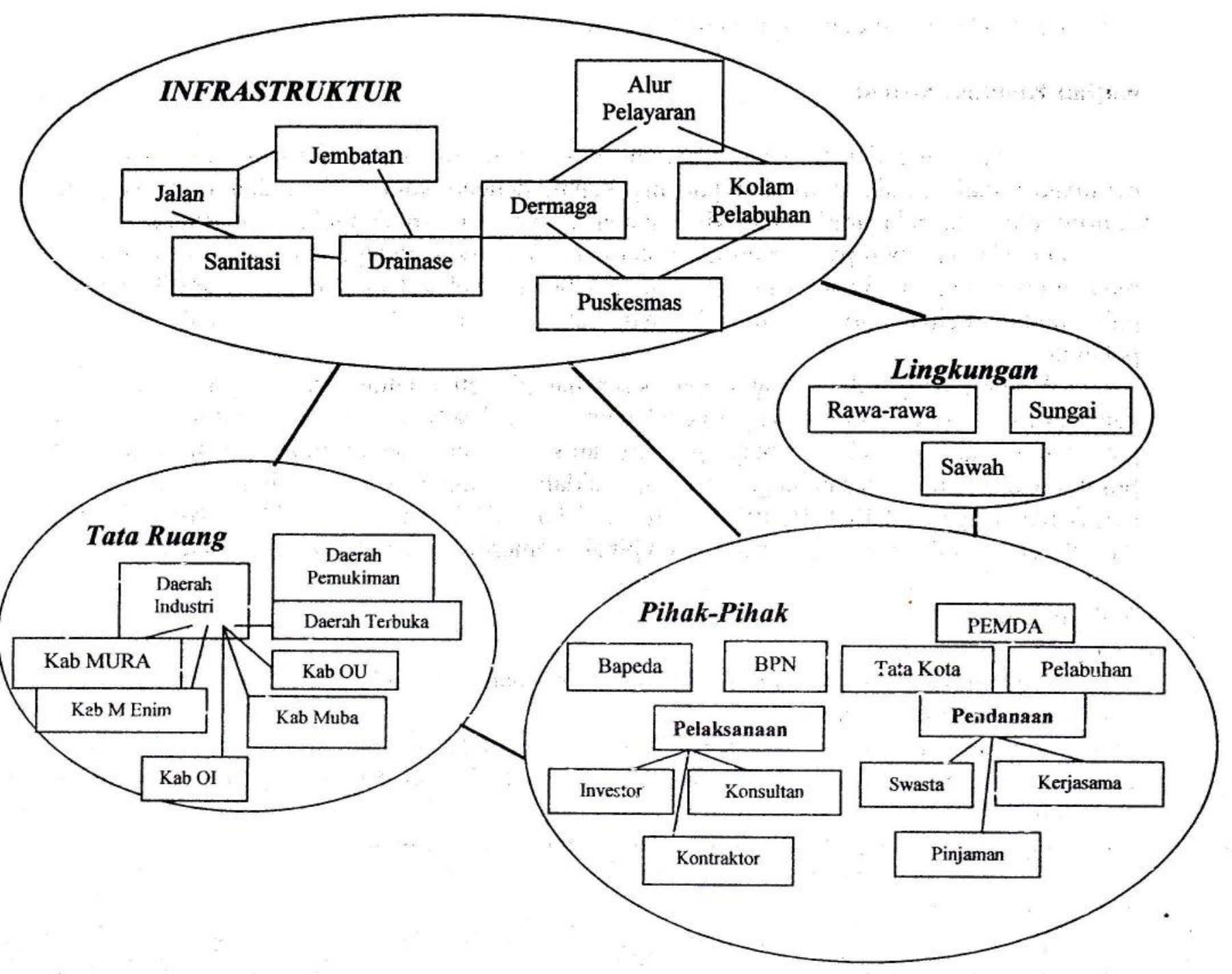

Gambar 1.Hirarki Sistem Pengembangan Pelabuhan Muatan Cair Sungai Lais Palembang

2. Sumber Daya Material.

Konsep perencanaan untuk total rencana pengembangan pelabuhan muatan cair mengacu pada aspek-aspek regional. topografi, batas lahan, termasuk ketersediaan air, fasilitas infrastruktur yang ada.

Untuk lahan kawasan pengembangan diatas diperlukan pematangan lahan dengan cara timbunan atau urugan, baik dengan pasir, tanah urugan maupun kombinasi keduanya. Pasir diharapkan dapat diperoleh dari pengerukan sungai Musi atau sungai lais, sedangkan tanah urugan didatangkan dari sekitar lokasi.

Untuk infrastruktur, material kerikil bisa didatangkan dari daerah kabupaten Lahat dan Cilegon, sedangkan material pasir didatangkan dari kabupaten Ogan Ilir. Material semen dari PT. Semen Baturaja, Tiga Roda dan Semen Padang, untuk besi dan didatangkan dari PT. 
Krakatau Stell. Material batu bata banyak tersedia didaerah Air Batu.Secara umum dapat dikatakan bahwa untuk pengadaan bahan-bahan material tidak menjadi kendala.

\section{Kajian Terhadap Kebutuhan Sistem}

Untuk mengoptimalisasi penanganan bongkar dan muat muatan cair maka dalam menentukan model pengembangan pelabuhan perahu layar sungai Lais menjadi pelabuhan muatan cair digunakan model kebutuhan sebagai berikut :

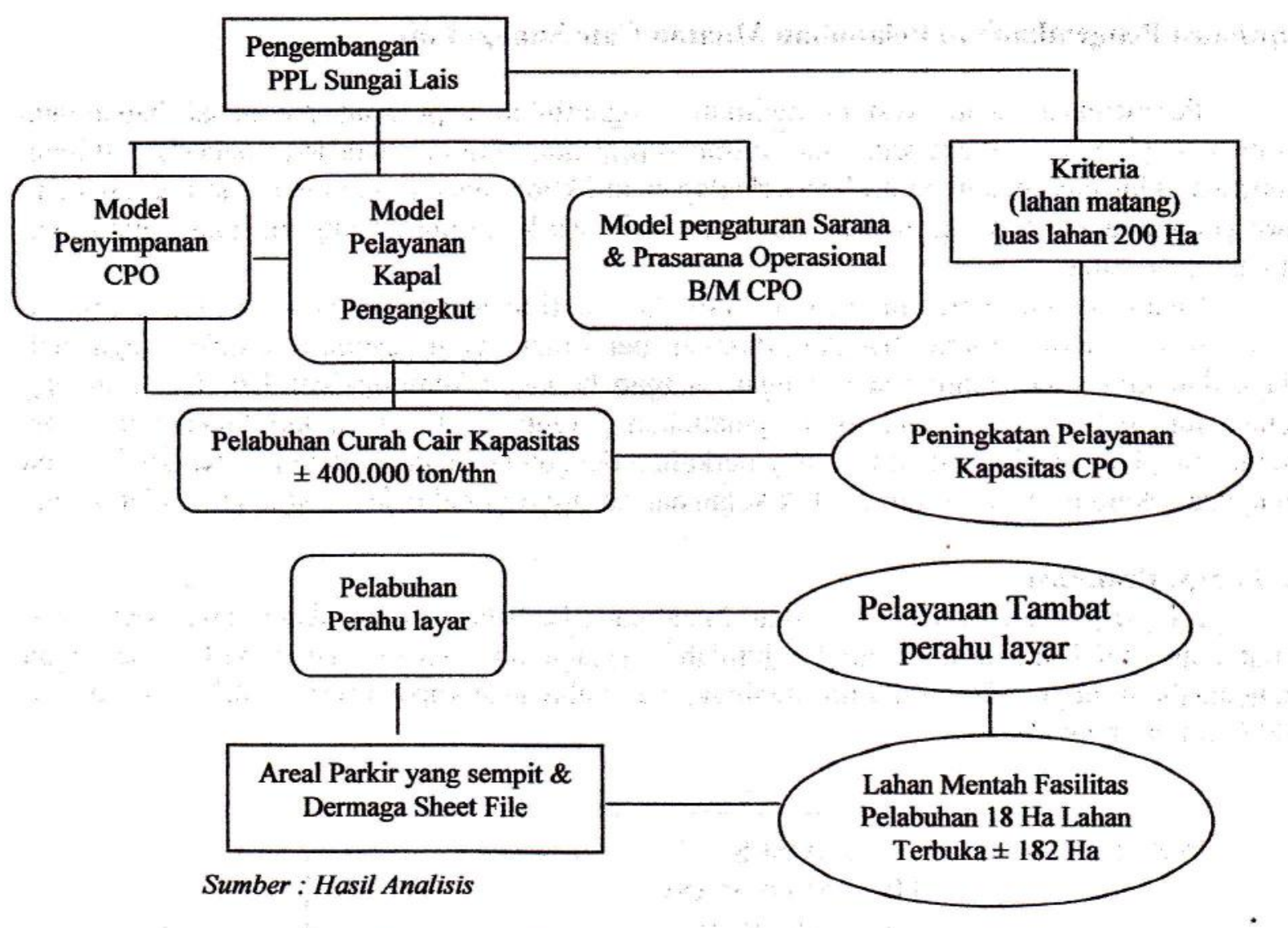

Gambar 2. Need model yang digunakan

\section{Model Pengembangan}

- Dalam usaha pemberdayaan fasilitas pelabuhan untuk pelayanan curah cair khususnya dipelabuhan Sungai Lais dibutuhkan model yang meliputi tangki timbun dan areal parkir, sementara yang tersedia saat ini hanya galangan kapal untuk tambatan perahu layar.

Kawasan yang baik harus merupakan satu kesatuan sistem organisasi, baik yang bersifat sosial, maupun fisik yang dirancang secara terpadu. Oleh karena itu maka kawasan sebaiknya jangan hanya direncanakan tapi harus juga dirancang. Adapun kebijakan-kebijakan program pengembangan yang diprogramkan di pengembangan Pelabuhan Muatan cair Sungai Lais akan di integrasikan dengan pengembangan perkotaan sehingga saling memberi efek positif bagi kota Palembang secara keseluruhan. 
Strategi Pengembangan yang akan dilaksanakan diantaranya adalah meningkatkan kerjasama pelayanan jasa dengan mitra dalam rangka peningkatan pangsa pasar, promosi usaha dan meningkatkan jaringan pemasaran, pemasaran aktif melalui pemberdayaan lahan, scenario pengembangan kawasan meliputi intern kawasan dan dan interaksi dengan kawasan lain dalam lingkup kota,aspek-aspek yang ditinjau mencakup aspek ekonomi, aspek teknik, aspek sosial dan aspek lingkungan serta perumusan komponen program melibatkan sektor swasta dan masyarakat dari sejak awal dalam hal pendanaan.

Penilaian terhadap pertumbuhan ekonomi akan memberikan arahan secara mendasar perlunya interprestasi pembangunan fisik baik infrastruktur dan sarana serta perencanaan penggunaan tata guna lahan dan perencanaan penggunaan ruang.

\section{Optimasi Pengembangan Pelabuhan Muatan Cair Sungai Lais}

Perencanaan suatu system meliputi pengambilan keputusan mengenai bagaimana sumber daya harus digunakan atau ditransformasikan untuk mencapai beberapa tujuan. Rencana akhir merupakan pemilihan terhadap suatui kombinasi tertentu dari sumber daya dan cara penggunaannya, yang diseleksi antara kombinasi-kombinasi yang ada untuk mencapai tujuan yang sama.

Suatu desain harus memenuhi sejumlah pertimbangan teknis,selain itu nilai-nilai ekonomi juga harus dipertimbangkan didalam pemilihan suatu desain, ditentukan juga oleh biaya dan nilai-nilai relative sehubungan dengan berbagai kemungkinan.Untuk menunjang kelancaran aktivitas para investor di pelabuhan perahu layar sungai lais.Maka kita harus mempersiapkan segala sesuatunya yang berkaitan dengan persiapan pelabuhan.Kondisi sarana yang ada sekarang sangat minim untuk kegunaan secara optimal dalam usaha jasa pelabuhan.

\section{Fungsi Produksi}

Fungsi produksi menggambarkan bagaimana berbagai sumber daya yang merupakan inputdalam hal inikebutuhan tangki, jumlah dermaga dan luasnya areal parker, sehingga menghasilkan output, dalam hal ini meningkatkan pelayanan kapasitas minyak sawit menjadi 400.000 ton / tahun.

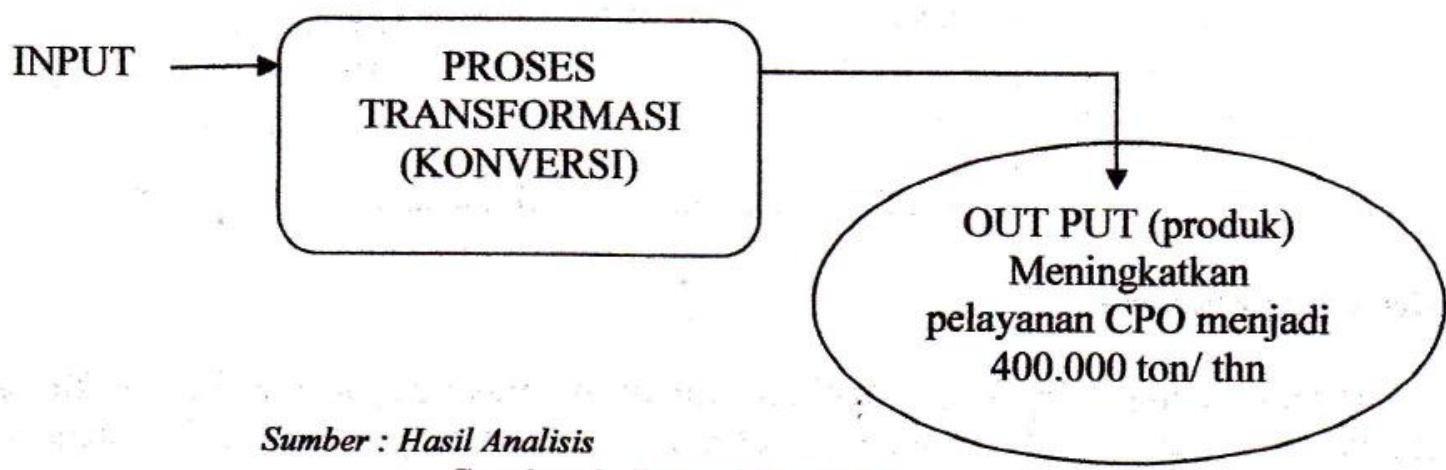

Gambar 3. Fungsi Produksi

Pelabuhan curah cair berkapasitas 400.000 ton/thn , dimisalkan sebagai fungsi produksi (Y)

Fungsi Produksi $(\mathrm{Y})=\mathrm{A} 1 \cdot \mathrm{X} 1+\mathrm{A} 2 \cdot \mathrm{X} 2+\mathrm{A} 3 \cdot \mathrm{X} 3$

Dimana : $\quad \mathrm{A1}=$ Jumlah tangki yang dibutuhkan

A2 = Jumlah tangki yang dibutuhkan

A3 = Jumlah tangki yang dibutuhkan 
$\mathrm{X1}=$ Tangki Timbun (kapasitas)

$\mathrm{X} 2$ = Dermaga Jetty

X3 = Areal Parkir

\section{Identifikasi Peluang- Peluang Investasi}

Keterbatasan dana pembangunan pemerintah sehingga diperlukan penyertaan danadana pembangunan baik itu dari swasta maupun dari masyarakat. Bila kita lihat dari segmen usaha, peluang pasar yang tinggi adalah daerah usaha terminal dan terminal peti kemas, karenanya cabang Palembang masih mempunyai peluang untuk meningkatkan kegiatan usaha terminal peti kemas maupun daerah usaha terminal.Adanya dukungan pemerintah untuk melengkapi infrastruktur yang memadai serta meningkatkan aksebility yang tinggi kemoda transportasi. Semakin meningkatnya pertumbuhan ekonomi yang dapat dilihat dari volume perdagangan dalam negeri yang semakin meningkat dan banyaknya volume arus bongkar muat barang dipelabuhan Boom Baru yang naik secara signifikan. Masih tersedianya lahan pengembangan yang masih disiapkan di Sungai Lais dan direncanakan Pemda di Tanjung Siapi-api.

\section{Evaluasi Investasi}

Dengan adanya usaha pengembangan pelabuhan muatan cair Sungai Lais diharapkan dapat memberikan nilai tambah baik bagi daerah sekitarnya maupun kota Palembang, karenanya diperlukan suatu analisis investasi agar optimasi system dapat menghasilkan sesuai dengan apa yang diharapkan.

\section{Analisa Sosial Budaya}

Peran serta masyarakat dilingkungan sekitar lokasi pengembangan sangat diperlukan untuk mencegah atau mengurangi resiko dampak sosial khususnya masalah keamanan dan dan pemeliharaan infrastruktur. Hal-hal yang perlu ditelaah dalam hal pengaruh pengembangan kawasan terhadap budaya sekitar diantaranya :

- Mengkaji hal-hal yang menjadi aspek positif masyarakat.

- Mengkaji pengalaman berkaitan dengan proyek terdahulu.

- Menelaah budaya yang berhubungan dengan institusi lokal.

- Menelaah hal-hal yang secara budaya dianggap rawan dan mudah membuat rancu budaya masyarakat.

Penduduk disekitar kawasan pelabuhan Sungai Lais tidak merasa keberatan PT.Pelindo II memanfaatkan lahan untuk kawasan pengembangan pelabuhan muatan cair, karena daerah disekitar masih merupakan lahan kosong dan penduduk yang bermukim disekitar lokasi masih sangat sedikit.

\section{Analisa Teknik}

Usaha pemanfaatan kawasan Sungai Lais dimaksudkan agar dapat meningkatkan pelayanan akan komoditi curah cair, yang berasal dari berbagai daerah di Sumatera Selatan diantaranya Kabupaten Musi Rawas, Kabupaten Musi Banyuasin, Kabupaten Ogan Ilir, kabupaten Muara Enim, Kabupaten Ogan Ulu. Daerah pengembangan pelabuhan Muatan Cair sungai Lais berada di kecamatan Sei selincah yang mempunyai luas sekitar \pm 200 ha yang terdiri dari lahan pemukiman, rawa-rawa, pergudangan dan sebagian masih tanah kosong. 
Untuk pembangunan segala infrastruktur yang ada tentunya membutuhkan biaya yang cukup mahal mengingat kondisi tanah lunak sebagai tanah dasar sehingga untuk lingkungan jalan masuk dan jalan lingkungan pelabuhan menggunakan aspal hotmix dengan terlebih dahulu diadakan perbaikan tanah asli seperti perbaikan dengan pasir, tanah sirtu dan tanah biasa dan mungkin juga diperlukan percepatan konsolidasi tanah dengan tiang pasir . Dengan adanya penimbunan, berarti adanya konpensasi dengan pembuatan drainase mulai dari limbah rumah tangga dan industri.

Disamping adanya kendala yang menaikan biaya investasi, lokasi pelabuhan Sungai Lais terletak pada kawasan yang mudah dijangkau dan dengan jarak yang tidak terlalu jauh dengan sungai Musi, sehingga memungkinkan untuk menjadi suatu kawasan pergudangan dan industri.

\section{Analisa Ekonomi}

Pengembangan pelabuhan muatan cair diharapkan dapat berdampak baik langsung maupun tidak langsung bagi perkembangan kegiatan perekonomian sekitar kawasan maupun kota Palembang secara keseluruhan.

Dari tinjauan aspek ekonomi, teknik dan sosial budaya, hasil evaluasi investasi adalah sebagai berikut:

- Kajian dari hasil evaluasi ekonomi dinyatakan layak untuk direalisasikan.

- Kajian dari hasil evaluasi aspek teknik dinyatakan dinyatakan bahwa rencana pengembangan pelabuhan muatan cair Sungai Lais memenuhi persyaratan teknik untuk dibangun infrastrukturnya

- Kajian dari hasil evaluasi aspek sosial budaya dinyatakan sangat baik dampaknya untuk masyarakat sekitar khususnya dan masyarakat Indonesia pada umumnya.

Dengan memperhatikan kajian terhadap berbagai aspek, dapat diambil suatu keputusan yang dievaluasi dengan menggunakan pohon keputusan ;

\section{Pohon Keputusan}

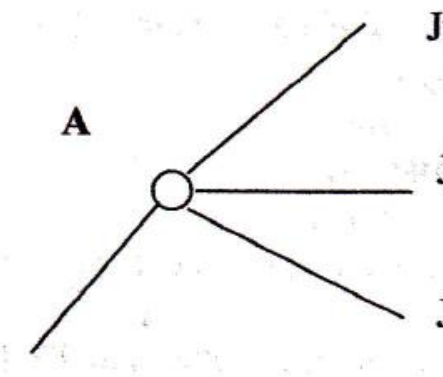

Jumlah CPO meningkat

$$
P 1=0,6
$$

Jumlah CPO tetap

$\mathrm{P} 2=0,3$

Jumlah CPO turun

$\mathrm{P} 3=0,2$ out came 1

8

out came 2

5

out came 3

2

Investasi dilakukan<smiles>COC(C)C</smiles>

Investasi tidak dilakukan

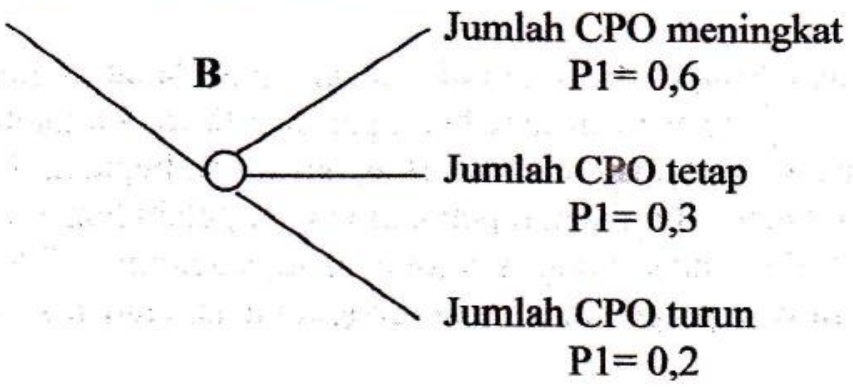

out came 1

2

out came 2

4

out came 3 


$$
\begin{aligned}
\mathrm{EV}(\mathrm{A}) & =\mathrm{P} 1(8)+\mathrm{P} 2(5)+\mathrm{P} 3(2) \\
& =0,6(8)+0,3(5)+0,2(2)=6,7
\end{aligned}
$$

$\mathrm{EV}(\mathrm{B})=\mathrm{P} 1(2)+\mathrm{P} 2(4)+\mathrm{P} 3(2)$

$$
=0,6(2)+0,3(4)+0,2(2)=3,6
$$

Jadi yang dipilih adalah alternative A dengan niai EV lebih tinggi yaitu 6,7

\section{KESIMPULAN}

- Rencana pengembangan pelabuhan muatan cair Sungai Lais berdasarkan evaluasi kelayakan aspek teknik, ekonomi dan sosial budaya dinyatakan layak untuk dibangun.

- Sumber daya yang ada seperti tersedianya lahan luas \pm 175 ha yang masih sangat memungkinkan untuk dapat dikembangkan.

\section{DAFTAR PUSTAKA}

Farida, Putih,2006 (hal12,15), "Analisa Sistem"

Idris, Yakni,2005 (hal 4), "Konsep Sistem Dan Pendekatan Sistem"

Taha, Hamdy,2010 (hal 10), "Riset Operasi", Binapura Aksara

Diktat Rekonfigurasi Pelabuhan Boom Baru dan Sungai Lais, 2002 (hal 6). PT. PELINDO II Cabang Palembang

Arikunto, Suharsini, 1998 (hal 17), "Prosedur Penelitian Suatu Pendekatan Praktek", Rineka Cipta, Jakarta

Sigit, Soehandi, 1999, "Pengantar Metodologi Penelitian"

Soekirno, P, 2008 (hal 1), "Manajemen Proyek Konstruksi", Bandung

Satyawan, Agly, 2012, https//id.scribd.com/doc/236422158, "Manajemen infrastruktuŕ", American Publik Works Association. 